\title{
Personalised 3D-printed model of a chest-wall chondrosarcoma to enhance patient understanding of complex cardiothoracic surgery
}

\author{
Laurence Weinberg, ${ }^{1,2}$ Moon Hae Pyo, ${ }^{3}$ Manfred Spanger, ${ }^{4}$ Stephen Arthur Barnett ${ }^{5}$
}

${ }^{1}$ Austin Hospital, Heidelberg,

Victoria, Australia

${ }^{2}$ Department of Surgery, Austin Health, University of Melbourne Melbourne, Victoria, Australia ${ }^{3}$ Department of Anaesthesia, Austin Health, Heidelberg, Victoria, Australia

${ }^{4}$ Box Hill Hospital, Box Hill, Victoria, Australia

${ }^{5}$ Cardiothoracic Surgery, Austin Health, Heidelberg, Victoria, Australia

Correspondence to Professor Laurence Weinberg, laurence.weinberg@austin. org.au

Accepted 7 May 2018
Check for updates

To cite: Weinberg $\mathrm{L}$, Pyo $\mathrm{MH}$, Spanger $\mathrm{M}$, et al. BMJ Case Rep Published Online First: [please include Day Month Year]. doi:10.1136/bcr-2018 224464

\section{DESCRIPTION}

Novel technologies, such as additive manufacturing (also termed three-dimensional (3D) printing), play an important role in surgical planning. Their role in enhancing a patient's understanding of their medical condition and increasing their satisfaction with their treatment is also gaining increased attention in medicine and surgery. As an illustration, we describe the case of a 65 -year-old Caucasian man who presented with left-sided anterior chest-wall pain which was associated with a visible palpable lump. He had a body mass index of $27 \mathrm{~kg} / \mathrm{m}^{2}$, and CT of the thorax demonstrated a $62 \mathrm{~mm} \times$ $60 \mathrm{~mm} \times 48 \mathrm{~mm}$ tumour involving multiple structures, including the left fourth to sixth ribs, costal cartilages and the pericardium overlaying the right ventricle (figure 1). Transthoracic echocardiography showed normal ventricular function without any indication of tumour infiltration into the myocardium.

Given the extensive involvement of neighbouring structures by this complex tumour, a 3D model was printed to enhance the patient's understanding of his medical condition (figure 2). The model was able to be easily appreciated by the patient without requiring the interpretation of 2-D CT images; it also enhanced the patient's understanding of the pathology and planned procedure. This played an important role in being able to provide informed consent for his surgery. The patient subsequently underwent a successful excision of the chondrosarcoma and an anterior chest wall reconstruction.
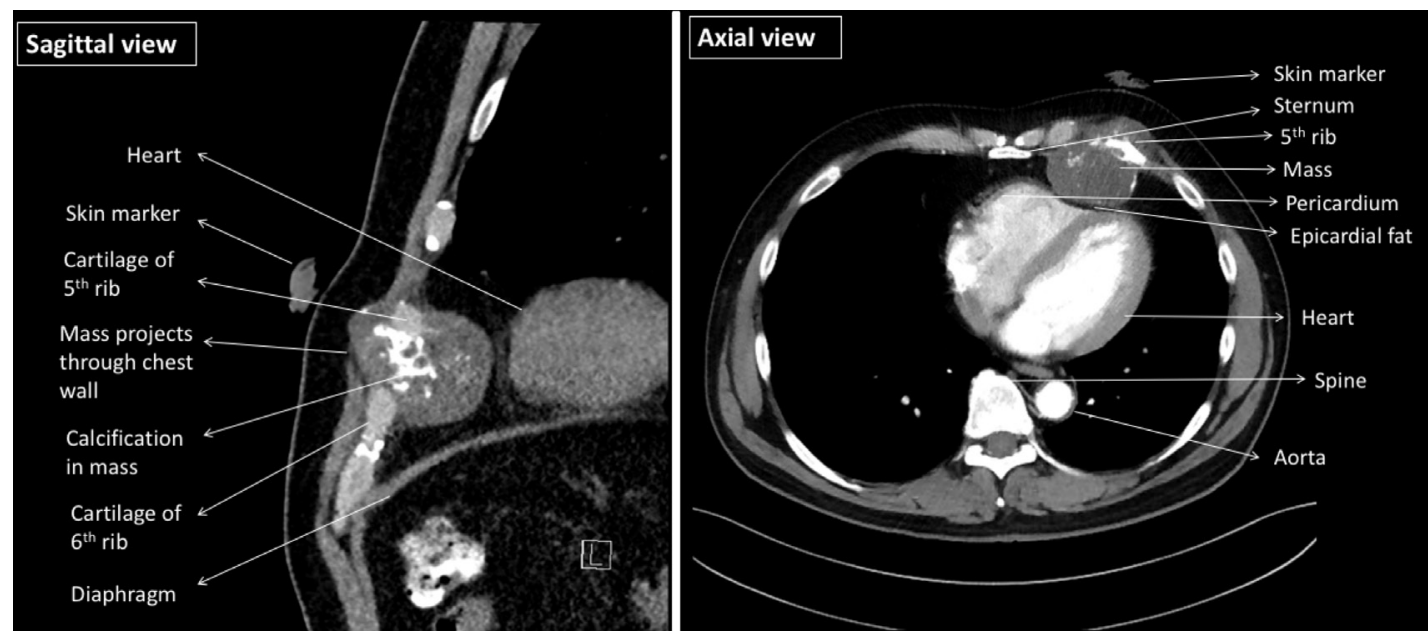

Figure 1 Axial (right) and sagittal (left) CT slices of the thorax demonstrating a large chondrosarcoma projecting through the chest wall.

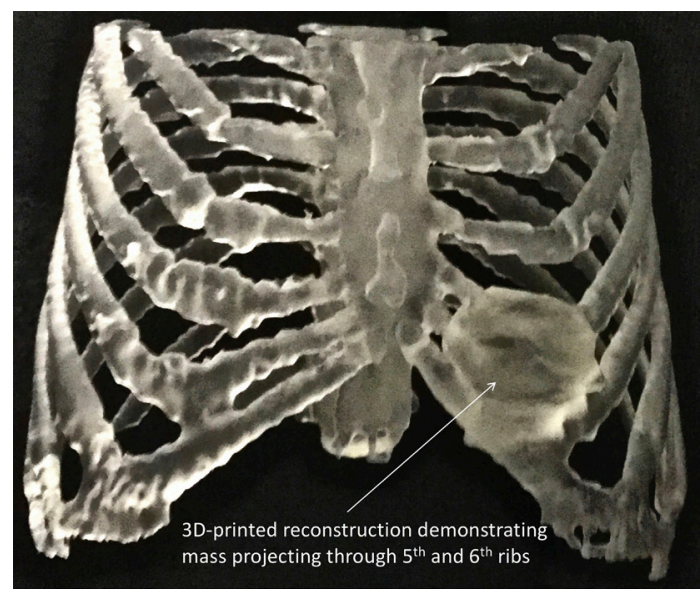

Figure 2 Three-dimensional (3D)-printed modelling of a chondrosarcoma of the chest wall.

Our case highlights the role of 3D printing in complex thoracic surgery. With its increasing availability, 3D printing has seen a growing relevance across many surgical specialties by producing surgical guides, custom implants and anatomical models. ${ }^{1}$ In particular, it is useful in preoperative planning, especially in complex surgeries where a high degree of precision is required. This may, in turn, result in lower complication rates, improved patient outcomes and reduced hospital stays.

Advantages of $3 \mathrm{D}$ printing in aiding communication over conventional communication are not 


\section{Patient's perspective}

After being diagnosed with a very rare cancer of my breastbone and ribcage, my doctor used a 3D-printed model to clearly explain to me what was causing my discomfort. Compared with the X-rays and scans which I found difficult to understand, the 3D-printed model allowed me to more easily appreciate what was wrong, and, more importantly, I could easily relay my diagnosis onto my family and friends. I also understood the size of the tumour and its location in my ribcage. Having a 3D model was comforting as I also felt that the doctor had a better visual view of exactly what he was dealing with prior to the operation. After surgery, the 3D model proved again to be very helpful. My surgeon used the model to explain exactly how the chondrosarcoma was removed, and also how the replacement titanium rib structure was constructed and fitted.

\section{Learning points}

- Three-dimensional (3D)-printing modelling is an effective too for communication with patients, allowing a greater level of understanding and knowledge about their pathology.

- The use of 3D-printed anatomical models can be extended to the medical education arena for medical students and specialty trainees.

- This can allow healthcare providers to better visualise and consolidate anatomical pathology and maximise their learning.

- 3D-printing modelling allows more precise surgical planning, which may, in turn, lead to improved patient outcomes.

known. In our case, the 3D-printed model facilitated a clear understanding of the pathology and planned procedure. Use of this evolving technology did not replace the manner in which we communicated information to the patient. Rather, it aided and complemented how the information was communicated, allowing the patient to acknowledge their health problem, and understand their treatment options. The 3D-printed model was an objective complementary strategy aiding our normal communication and consent processes.
At present, 3D printing is associated with an increased cost for procedures. However, 3D-printing modelling has been known to facilitate a more rapid understanding of anatomy compared with conventional media. ${ }^{23}$ It serves as a valuable tool of communication with patients and may be a useful resource in multidisciplinary team coordination for discussing the pathology involved in a surgical procedure. Further, uses of visual technologies such 3D printing may help overcome hurdles arising from linguistic and cultural differences. Finally, although this modality remains in its infancy, current literature suggests improved outcomes in education compared with traditional educational methods. ${ }^{4}$ With the continual implementation and enhancement of this technology, it is expected that 3D printing will play a significantly more prominent role in anatomical and surgical patient education in the future.

Contributors LW was the principal anaesthetist responsible for the management of the case. He assisted with the literature review, writing of the manuscript and preparation of all images. SAB was the principal cardiothoracic surgeon responsible for the management of the case. He assisted with the writing of the manuscript and preparation of all images. MS was responsible for the interpretation of all radiological images. He assisted with the writing of the manuscript and preparation of all images. MHP assisted with the literature review and writing of the manuscript. All authors have read and approved the final manuscript.

Funding The authors have not declared a specific grant for this research from any funding agency in the public, commercial or not-for-profit sectors.

Competing interests None declared.

Patient consent Obtained.

Provenance and peer review Not commissioned; externally peer reviewed. (c) BMJ Publishing Group Ltd (unless otherwise stated in the text of the article) 2018. All rights reserved. No commercial use is permitted unless otherwise expressly granted.

\section{REFERENCES}

1 Tack P, Victor J, Gemmel P, et al. 3D-printing techniques in a medical setting: a systematic literature review. Biomed Eng Online 2016;15:115.

2 Cromeens BP, Ray WC, Hoehne B, et al. Facilitating surgeon understanding of complex anatomy using a three-dimensional printed model. J Surg Res 2017;216:18-25.

3 Hermsen JL, Burke TM, Seslar SP, et al. Scan, plan, print, practice, perform: development and use of a patient-specific 3-dimensional printed model in adult cardiac surgery. scan, plan, print, practice, perform: development and use of a patient-specific 3-dimensional printed model in adult cardiac surgery. J Thorac Cardiovasc Surg 2017:153:132-40.

4 Langridge B, Momin S, Coumbe B, et al. Systematic review of the use of 3-dimensional printing in surgical teaching and assessment. J Surg Educ 2018;75:30183-6.

Copyright 2018 BMJ Publishing Group. All rights reserved. For permission to reuse any of this content visit

http://group.bmj.com/group/rights-licensing/permissions.

BMJ Case Report Fellows may re-use this article for personal use and teaching without any further permission.

Become a Fellow of BMJ Case Reports today and you can:

- Submit as many cases as you like

- Enjoy fast sympathetic peer review and rapid publication of accepted articles

- Access all the published articles

- Re-use any of the published material for personal use and teaching without further permission

For information on Institutional Fellowships contact consortiasales@bmjgroup.com

Visit casereports.bmj.com for more articles like this and to become a Fellow 